\title{
Politique
}

\section{Graham Fraser, Le Parti québécois, Montréal, Libre} Expression, 1984, 432 p.

\section{Jean-Pierre Beaud}

Numéro 8, automne 1985

Innovations et politiques technologiques

URI : https://id.erudit.org/iderudit/040505ar

DOI : https://doi.org/10.7202/040505ar

Aller au sommaire du numéro

Éditeur(s)

Société québécoise de science politique

ISSN

0711-608X (imprimé)

1918-6584 (numérique)

Découvrir la revue

Citer ce compte rendu

Beaud, J.-P. (1985). Compte rendu de [Graham Fraser, Le Parti québécois, Montréal, Libre Expression, 1984, 432 p.] Politique, (8), 160-162.

https://doi.org/10.7202/040505ar

Ce document est protégé par la loi sur le droit d'auteur. L'utilisation des services d'Érudit (y compris la reproduction) est assujettie à sa politique d'utilisation que vous pouvez consulter en ligne.

https://apropos.erudit.org/fr/usagers/politique-dutilisation/
Cet article est diffusé et préservé par Érudit.

Érudit est un consortium interuniversitaire sans but lucratif composé de l’Université de Montréal, l'Université Laval et l'Université du Québec à Montréal. Il a pour mission la promotion et la valorisation de la recherche. https://www.erudit.org/fr/ 
Graham Fraser, Le Parti québécois, Montréal, Libre Expression, 1984, 432 pages.

Contrairement à ce que le titre français très laconique suggère, le livre de Graham Fraser n'est pas vraiment consacré à l'étude d'un parti, du moins au sens où l'entend la science politique. Ainsi on y apprend peu de choses sur les structures du Parti québécois, sur le militantisme au sein de l'organisation, sur la vie et les caractéristiques des quelques dizaines de milliers de membres. Le titre original anglais est déjà plus fidèle au contenu: $P Q$. René Lévesque and the Parti Québécois in Power. De fait, l'histoire du Parti québécois que nous propose le journaliste du Globe and Mail, c'est l'histoire d'un parti vue à travers le prisme du leader et des quelques personnes qui l'ont entouré: d'où la richesse (le texte est très vivant et nous restitue dans ses moindres détails la vie d'un dirigeant politique important), mais aussi les limites de l'ouvrage (que sait-on de ce qu'ont vécu les troupes péquistes?).

Riche, le texte l'est d'abord par l'abondance des faits rapportés: les grands événements de la vie politique provinciale et même fédérale, les grands débats qui ont «travaillé» le parti, les luttes internes (essentiellement celles opposant les élites du parti entre elles), les conflits de personnes, les points de vue des leaders sont soigneusement présentés, analysés, classés, replacés dans la chronologie. Cette histoire de ceux qui, dit-on, font l'Histoire, Fraser s'attache à la reconstruire le plus fidèlement possible. Une telle synthèse fera sans aucun doute autorité.

Riche, le texte l'est également par les matériaux rassemblés et donc par les possibilités de recherche qu'il fournit. Les biographies reconstituées par l'auteur, les données nombreuses concernant les liens familiaux, amicaux, l'origine sociale, les lieux d'instruction, les diplômes, les trajectoires sociales, les cursus partisans devraient, par exemple, permettre l'élaboration d'une sociologie des dirigeants péquistes et plus généralement des élites politiques québécoises. 
Les limites de l'ouvrage, quant à elles, tiennent essentiellement à la conception de l'histoire que Fraser met de l'avant implicitement. Tout d'abord, et c'est son droit, l'auteur choisit de faire une lecture de l'histoire politique qu'on pourra qualifier de traditionnelle: ce sont les «grands personnages» qui retiennent son attention, c'est autour d'eux que s'ordonnent les événements. Une telle conception n'est pas en soi à rejeter: s'il est vrai qu'il y a inégalité de la distribution du pouvoir (et donc du pouvoir d'agir, de parler), retenir les acteurs "puissants» se justifie. Il est clair, par exemple, que la vie, même privée de René Lévesque nous concerne (nous concernait!). Ce qui, par contre, est critiquable, c'est de ne pas tirer les conséquences de ce choix, les limites d'une telle lecture, de ne pas au moins faire référence à d'autres lectures possibles. Or, en l'occurrence, de ces autres lectures Fraser ne parle pas; ces autres acteurs (les «masses»), Fraser ne les fait apparaitre que rarement et plus comme consommateurs que comme producteurs d'événements: ainsi les sympathisants péquistes crient, acclament et célèbrent leur joie le 15 novembre 1976 (p. 11), les délégués au Congrès retiennent leur souffle lorsqu'apparaît Jacques Parizeau (p. 331), la salle est soulagées après le discours de Lévesque et cela est émouvant à voir (p. 371), ... Le point de vue adopté par Fraser, c'est donc celui des dirigeants, ces hommes «brillants et complexes» (Camille Laurin, Jacques Parizeau, Claude Morin), «exceptionnels» (Claude Ryan, Robert Bourassa, Pierre Trudeau), voire «grandioses», «mythiques», "charismatiques» (René Lévesque). Leur répondent, de loin en loin, des masses en fait quasi subjuguées (Camille Laurin serait ainsi un personnage messianique pour les Québécois de langue française, p. 127).

Cette conception élitiste, donc, de l'histoire se double, cela n'est pas étonnant, d'une conception psychologique, idéaliste, volontariste. Fraser, et c'est sans doute ce qui donne beaucoup de vie à son texte, ne se contente pas de recenser les caractéristiques sociales des élites: il chercher aussi et surtout à dégager les traits 
de caractère de ces grands acteurs (il fait, par exemple, de René Lévesque un véritable Dr. Jekyll et Mr. Hyde de la politique!). Le problème, c'est qu'il semble, trop souvent, trouver dans les qualités et défauts de ces personnages la clé des événements politiques, qu'il recourt trop souvent à des explications en termes de nature humaine (dons, instincts) ou vaguement psychanalytiques (pp. 30, 32, 37, 144, 161, ..).

Le texte, plutôt long (432 pages) mais jamais ennuyeux de Fraser, n'est pas non plus sans contenir certaines analyses contestables. Ainsi il n'est pas sûr que l'on puisse dire que «... 2500 personnes qui, en 1976, avaient donné leur appui au Parti québécois, ne s'étaient pas présentées pour voter» sous prétexte que JeanClaude Rivest avait reçu le 30 avril 197914684 votes, soit 350 de plus que Raymond Garneau à l'élection précédente, alors que le vote de Louise Beaudoin était tombé de 11532 à 8936 (p. 196)! On peut également se demander si le pointillisme de l'auteur, son sens du détail (la marque de cigarettes de Lévesque, la couleur de sa limousine, l'heure précise de tel événement, ...), qui tiennent sans doute au fait que certains chapitres ont d'abord été écrits pour des magazines, n'a pas pour conséquence de noyer les analyses, les faits les plus importants, et en particulier la thèse centrale, bien étayée, d'un gouvernement aussi décevant dans son deuxième mandat qu'inventif dans le premier.

Il faut saluer en terminant l'ampleur du travail réalisé par Graham Fraser: il nous donne là une lecture captivante de l'histoire du parti de René Lévesque.

Jean-Pierre Beaud

Université du Québec à Montréal 